\title{
Lactobacillus brevis CD2 Lozenge
}

National Cancer Institute

\section{Source}

National Cancer Institute. Lactobacillus brevis CD2 Lozenge. NCI Thesaurus. Code C99229.

A lozenge containing an extract from the Lactobacillus brevis (L. brevis) with potential anti-inflammatory activity. As L. brevis CD2 contains high levels of arginine deiminase, which catalyzes the conversion of arg inine to citrulline and ammonia, administration of this lozenge leads to hydrolysis of arginine in the oral cavity. The growth of bacteria, which depends on arginine, is halted, polyamine biosynthesis is reduced and the production of nitric oxide (NO) is reduced. The reduction in NO generation may further prevent inflammation in the oral cavity. Therefore, this agent may be able to reduce chemo- and radiotherapy-induced mucositis. 